\title{
Development of Creative Thinking Skill Instruments for Chemistry Student Teachers in Indonesia
}

\author{
https://doi.org/10.3991/ijoe.v15i14.11354 \\ M. Dwi Wiwik Ernawati ( ${ }^{\bowtie}$, Damris M., Asrial, Muhaimin \\ University of Jambi, Jambi, Indonesia \\ wwkchem2@yahoo.co.id
}

\begin{abstract}
Creative thinking is a mental activity to build idea/ideas in dealing with problems. It improves self-confidence, academic achievements, and career success. The creative thinking is complex in nature and its measurement involving many aspects of flexibility, originality, fluency, elaboration, sensitivity and imagination. These aspects are parameters of creative thinking measurement. Development of the creative thinking instrument involves those aspects and should be adjusted to the purpose, method and time of use. Measurement of students' creative thinking skills in learning requires a new instrument that covers all the above-mentioned aspects. The instrument was developed following Borg and Gall model. The instrument was then used in learning processes that applied problem based-learningscaffolding models. Development results instrument, consisting of 16 items with each of them has four multilevel score scores. Based on the results of the validity of the items at the stage of limited empirical test and extensive trial, al items were also declared valid, with a score above the rxy table value $(0.34)$ The instrument also shows a high level of reliability with a r11 value of 0.75 , from the extensive testing phase. Means that the instrument developed has fulfilled standard instrument standards.
\end{abstract}

Keywords-Instrument Development, Creative Thinking, Borg and Gall model.

\section{Introduction}

Creative thinking is a mental activity to build new ideas or ideas, which are useful in dealing with problems and problems that occur. Creative thinking can provide confidence and improve academic achievement [1], and is an integral component to achieving career success, as well as success in an organization [2]. Similarly, according to [3], creative thinking needs to be done because this ability is one of the skills desired by the workforce. This shows that creative thinking is important and must be owned by each individual in order to solve life's problems that are increasingly complex in the current era of globalization. 
The importance of the ability to think creatively has been demonstrated by the many studies, including: [3] measuring the creativity of children aged 5-15 years, in terms of aspects of fluency, flexibility and originality, while elaboration only appears in non-verbal activities. According to [1] creative thinking is more related to trust practices, which believe that both products and processes have an impact on creative thinking, which can be known through reading, writing and expressing themselves so that it helps develop elaboration skills. [1] Also said that creative thinking can stimulate curiosity and promote difference. In creative thinking will involve the skills of flexibility, originality, fluency, elaboration, brainstorming, modification, image, associative thinking, attribute list, metaphorical thinking, and there is a very strong relationship between each other. Similarly, according to [4], the creative thinking process requires sensitivity, fluency, flexibility, originality, elaboration, and imagination. According to him there is a relationship between the ability to think creatively with creative personality. For that aspect of sensitivity, fluency, flexibility, originality and elaboration can be used as parameters for creative thinking [5]

So, to know someone's creative thinking ability, it is necessary to develop instruments that cover the above aspects. According to [6], [7], [8] and [9], an assessment instrument developed, must be adjusted to the purpose, method, and time of use, and standardized based on item validity and has high reliability.

Based on the description above, an instrument for assessing creative thinking skills will be carried out covering aspects of sensitivity, fluency, flexibility, originality and elaboration. The instrument will be used to measure creative thinking skills through verbal activities, namely the delivery of creative thinking in the form of words [10]. So that the instrument can be used as an observation tool for learning activities, and a self-assessment questionnaire.

\section{Development Method}

The development of this creative thinking instrument follows the Borg and Gall model, with steps that have been modified by [11]. The development steps are shown in Figure 1.

At the theoretical review stage, a study was carried out on: characteristics and aspects of creative thinking, standards for developing learning outcomes assessment instruments, and supported by research results relevant to the development of creative thinking instruments. Furthermore, at the construct stage, the form and model of creative thinking instruments will be determined according to their use as an observation instrument and self-assessment questionnaire, title position, implementation identity, usage manual and user signature. Whereas at the stage of making the instrument grid, there will be development of indicators of aspects of creative thinking (sensitivity, fluency, flexibility, originality, and elaboration), with regard to the characteristics of the instrument (representative and proportional). Then proceed with the development of instruments. In the expert test phase, material validation, constituency and language will be carried out. Furthermore, in limited empirical trials and extensive trials, the instrument will be used to observe 
Biochemical lecture activities based on problems with scaffolding, as well as selfassessment after attending lectures that are displayed in questionnaires

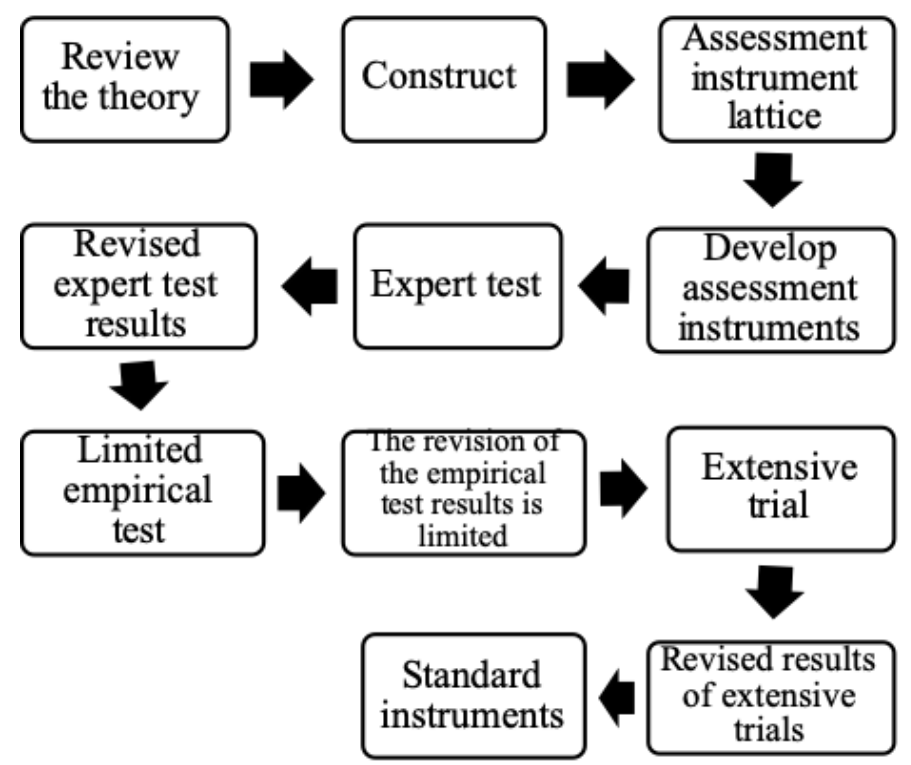

Fig. 1. Development steps

Qualitative data from the development of instruments, in the form of suggestions and responses are used to revise. While the quantitative data from the limited empirical test stage and the results of extensive trials, in the form of observations and self-assessment of item validity, were processed using the correlation formula product moment $\left(\mathrm{r}_{\mathrm{xy}}\right)$ and $\mathrm{r}_{11}$ for the determination of instrument reliability.

\section{Development Results}

The process of developing instruments for assessing creative thinking skills following the Borg and Gall design model modified by [11] consists of 11 stages, namely:

\subsection{Review the theory}

The results of theoretical analysis for the development of creative thinking instruments are shown in Table 1. 
Table 1. Results of literature studies

\begin{tabular}{|c|c|c|}
\hline No. & Data & Hasil \\
\hline 1. & $\begin{array}{l}\text { Creative thinking } \\
\text { aspects }\end{array}$ & $\begin{array}{l}\text { Sensitivity, fluency, flexibility, originality, and elaboration (Almeida et al. } \\
\text { (2008); (Lee, 2005); Wang (2011); JP Guilford in Runco and Pritzker (1999, p. } \\
\text { 11)). }\end{array}$ \\
\hline 2 & Instrument type & $\begin{array}{l}\text { Observation (verbal test: thinking creatively with words (Torrance and Ball } \\
\text { (1984); Davis (2012, p. 81)) and self-assessment questionnaires. }\end{array}$ \\
\hline 3. & Standard instrument & $\begin{array}{l}\text { Valid, reliable, relevant, representative and proportional [] ((Arifin, 2013; } \\
\text { Wahidmurni et al., 2010)) }\end{array}$ \\
\hline 4. & Validity & $\begin{array}{l}\text { Expert validation (substance, construct and language) and item validation } \\
\text { Substances that present the competencies assessed, } \\
\text { Construction that meets technical requirements in accordance with the shape of } \\
\text { the instrument used } \\
\text { The language used must use good and true, and communicative language. } \\
\text { Validity of items, determined based on the results of the observer's assessment } \\
\text { and self-assessment. }\end{array}$ \\
\hline 5. & Cognitive Level & C-6 (creativity) Anderson's taxonomy \\
\hline 6. & Development style & $\begin{array}{l}\text { The Borg and Gall development model that has been modified by [] Supardi } \\
(2014 \text {, p. 292) }\end{array}$ \\
\hline
\end{tabular}

Throughout the experience of researchers, in the Jambi University Chemistry Education Study Program, there has never been an assessment of students' creative thinking skills, which is achieved due to the application of a learning model. Then an instrument of assessment of creative thinking skills will be developed which will be used to observe the implementation of learning in Biochemistry courses based on problems with scaffolding. The instrument will also be used as a self-assessment questionnaire.

\subsection{Construction}

The construct stage results, in the form of an instrument of assessment of creative thinking skills that includes aspects of sensitivity, fluency, flexibility, originality and elaboration. The instrument can be used to measure students' creative thinking skills through verbal activities, namely in the form of words (the delivery of creative thinking results) during learning. The instrument will be used as a tool for observing student activities in following Biochemistry learning that applies problem-based learning models with scaffolding, and self-assessment questionnaires. On the sheet of creative thinking instruments, there are: are:

a) Title: "observation sheet /questionnaire creative thinking of students". Located in the upper middle, appears in bold capital letters.

b) The implementation identity is located under the heading, upper left. The observation sheet consisted of: name of course, material, semester, meeting, day / date, observer and instructions. Whereas the questionnaire consists of: name of course, semester, name, NIM, day / date and instructions.

c) Formulation of filling instructions (specifically for questionnaires): 
- Give a checklist $(\sqrt{ })$ in the column $\sqrt{ }$ and give a reason according to the criteria you have!

- Give a reason for the answer you chose!

\subsection{Making instrument lattices}

At this stage the development of indicators from creative thinking aspects is shown in table 2 , instrument lattice.

Table 2. Lattices of creative thinking instruments.

\begin{tabular}{|c|c|c|}
\hline Creative thinking aspects & No & Indicator \\
\hline \multirow{3}{*}{ Sensitivity } & 1. & Speed and accuracy for asking questions. \\
\hline & 2. & Speed and accuracy for responding to questions. \\
\hline & 3. & $\begin{array}{l}\text { Speed and accuracy for making conclusion of the problems being } \\
\text { discussed }\end{array}$ \\
\hline \multirow{3}{*}{ Fluency } & 4. & Spark many ideas in solving problems. \\
\hline & 5. & Provide many ways or suggestions to do various things. \\
\hline & 6. & Work faster and do more in solving problems. \\
\hline \multirow{3}{*}{ Flexibility } & 7. & Produce a problem-solving idea or answer a variety of questions. \\
\hline & 8. & Can see a problem from different points of view. \\
\hline & 9. & $\begin{array}{l}\text { Presenting a concept in a different way (with slate from presentation } \\
\text { style, expression or expression. }\end{array}$ \\
\hline \multirow{3}{*}{ Originality } & 10. & Give new ideas in solving problems. \\
\hline & 11. & Develop or enrich the ideas of others. \\
\hline & 12. & Add or specify an idea so as to improve the quality of the idea. \\
\hline \multirow{4}{*}{ Elaboration } & 13. & $\begin{array}{l}\text { Can determine the truth of a truth of the question or the truth of a } \\
\text { problem-solving plan. }\end{array}$ \\
\hline & 14. & Can trigger ideas to solve a problem and can implement it correctly. \\
\hline & 15. & Having a reason that can be accounted for to reach a decision. \\
\hline & 16. & Express the reasons for the truth of the answers / statements. \\
\hline
\end{tabular}

\subsection{Develop assessment instruments}

The results of the development in the form of a sheet of instruments to assess creative thinking skills, consisting of:

- The title: located in the upper middle, appears in bold capital letters

- Implementation identity: located under the heading, upper left

- Instructions for filling: are parallel to the same code and continuation of the implementation identity

- The contents of the instrument for assessing creative thinking skills are presented in columns, and consist of: aspects, serial numbers, indicators of creative thinking aspects, selection descriptors of assessment results, groups and student codes, as well as observer comments columns for each indicator achievement (specifically for observation instruments). While the self-assessment instrument, there is no 
group column, and the name of the student is located in the identity of the implementation.

- Name and signature of the user (observer / student), in the lower right corner

\subsection{Expert test}

Validation of substance: The substance validation process was carried out three times. In stage one, the suggestions for improvement are time changes for sensitivity descriptors. Descriptors with a score of one, for numbers 3, 4, 5, 6, 7, 12, 13, and 15 do not describe ownership of creative thinking skills. Then the revision is carried out according to the suggestions.

In stage two validation, there are still descriptors that do not match the score level, that is for score 4 of indicator number 10, adding words enriching the ideas of others. And need additional indicators for sensitivity aspects.

In stage three validation, the expert stated that the instrument for assessing creative thinking skills from the development results had met the evaluation criteria, with the predicate very well and worthy of being tested.

Validation of the construct: Construct validation is done twice. The suggestion given by the validator is the suitability of the form of the table on the effectiveness of the use by observers, because of one observer, observing two groups. The title changes by using the term creative thinking skills. And eliminate the term effective and efficient on indicator number 8 .

In stage two validation, the validator stated that the instrument for assessing creative thinking skills developed had met the construct aspect evaluation criteria, with very good prediction.

Language validation: Language validation, also takes place in two stages. The advice given in the form of uniform use of the term and the accuracy of the use of punctuation.

\subsection{Revised expert test results}

Revision of substance validation: At stage one, revisions made regarding suggestions are changes in time to think about problems or solutions, in sensitivity descriptors is time $\leq 0.5$ minutes for score 4 . Descriptors with score one, for numbers $3,4,5,6,7,12,13$, and 15 , have described the existence of creative thoughts or ideas.

In stage two, the revision for score 4 from indicator number 10 becomes "giving new ideas correctly, which can enrich other people's ideas". As for the sensitivity aspect, the addition of indicators is carried out, from two to three.

Revision of construct validation: The revision of the results of the first phase of the construct validation is to add a group table and members on the right, so that the observer's work is more effective. While the title turns into an instrument for assessing creative thinking skills. Indicator number 8 , does not use the term effective and efficient. 
Revision of language validation: The results of the language validation revision, namely homogenizing the use of terms and placing the use of punctuation in accordance with the correct Indonesian spelling rules.

\section{7 $\quad$ Limited empirical testing}

Limited empirical tests were carried out on 10 students who attended Biochemistry I, 2016-2017 academic year at the Jambi University Chemistry Education Study Program, which was observed by 3 observers. Learning is carried out with 12 meetings. At the end of the learning, students were asked to fill out a questionnaire instrument for assessing creative thinking skills.

Data from observer assessment and student questionnaire were used to determine the level of item validity and instrument reliability. The results of the analysis show that the highest level of validity is item number 8 with the average $r_{x y}$ value of 0.83 while the lowest level of validation is in item number 3 with the average $r_{x y}$ value of 0.72 . Means that all items are declared valid because the $r_{x y}$ value is above $r_{\text {table }}(0.71)$. The results of the reliability calculation show very high criteria with a $r_{11}$ value of 0.91 .

\subsection{Revised empirical test results are limited}

Based on the limited empirical test results, there is no revision of the overall items of instrument thinking creatively both quantitatively and qualitatively, so that development can be continued at the extensive testing stage.

\subsection{Extensive trial}

Extensive trials were carried out on 36 regular class students who attended Biochemistry I who applied problem-based learning models with scaffolding, in the 2016-2017 academic year at the University of Jamb Chemistry Education Study Program, involving 6 observers. Learning is carried out with 12 meetings. At the end of the lesson, students were also asked to fill out a questionnaire on instruments for assessing creative thinking skills.

The results of the analysis show that the validity level of each item is above the $r_{x y}$ table value (0.34), meaning that all items are declared valid. While the reliability of the instrument shows a high criterion with a r11 value of 0.75 .

\subsection{Revised the results of extensive trials}

Based on the results of extensive trials, there was no revision so that the instrument for assessing creative thinking skills developed could be said to be a standard instrument. 


\subsection{Standard instruments}

The instrument of assessment of creative thinking skills as a result of development, consists of 16 items with each having four multilevel score scores. The instrument of assessment of creative thinking skills includes five aspects: sensitivity, fluency, flexibility, originality, and elaboration. The instrument has been declared valid, both by experts (substance, construct and language) and from the results of testing the validity of items at the stage of limited empirical testing and extensive trials. The instrument also has high reliability from the extensive trial phase.

\section{Discussion}

Assessment instruments are data collection tools that are used to find out the results achieved in an activity. According to [6], [7], [8], and [9] instrument can function to determine the effectiveness of a learning process. According to them, the instrument used must also be adjusted to the function, method and time, meaning that to know the effectiveness of a process, it is necessary to develop the assessment instruments needed.

The development of assessment instruments in this study aims to find out the creative thinking skills of students in learning that apply problem-based learning models with scaffolding. The assessment instrument will also be used as a selfassessment questionnaire. The development process follows the Borg and Gall research and development model, with measures modified by [11] because the model is specifically for instrument development.

Development results instrument, consisting of 16 items with each of them has four multilevel score scores. The instrument includes a type of multiple-choice objective writing test [9]. According to him the instrument has advantages: objective, scoring is easier and faster, relatively inexpensive, especially if used for a wide scale.

The instrument of assessment of creative thinking skills includes five aspects: sensitivity, fluency, flexibility, originality, and elaboration. These aspects are chosen in accordance with the results of research conducted to determine one's creativity, such a [12] has conducted research to determine the creativity of children and preadolescents aged 5-15 years. According to him the inconsistency of cognitive processes (smoothness, flexibility, originality and elaboration) as the main cognitive factors for determining and assessing creativity. The cognitive processes that tend to be present in creativity are fluency, flexibility and originality. While the elaboration process can be identified in several tasks and usually appears in non-verbal activities.

However, creative thinking can stimulate curiosity and promote difference [1]. In creative thinking will involve the skills of flexibility, originality, fluency, elaboration, brainstorming, modification, image, associative thinking, attribute list, metaphorical thinking, and there is a very strong relationship between each other.

Similarly, according to [4], the creative thinking process requires sensitivity, fluency, flexibility, originality, elaboration, and imagination. According to him there is a relationship between the ability to think creatively with creative personality. For 
that aspects of sensitivity, fluency, flexibility, originality and elaboration can be used as parameters for creative thinking [5]

According to [7], the characteristics of good instruments must have validity, reliability, objectivity and economic objectivity. These characteristics have been found in the assessment instrument of creative thinking as a result of development. The instrument has been validated, by material experts, constructs and languages. The material validation process was carried out three times, while construct validation and language were only done twice. This is supported by [13] namely, validity must be fulfilled in writing questions covering three aspects, namely material, construction, and language. Aspects that are used as parameters for creative thinking, then developed into indicators of achievement, and arranged in the form of instrument lattices. Referring to the instrument lattice means that the developer has tried to fulfill the material validity, because then the grid will be used as a guide to formulate the questions/ instrument statements [6].

Based on the results of the validity of the items at the stage of limited empirical testing and extensive trials, all instrument items also showed values, above the $\mathrm{r}_{\mathrm{xy}}$ table (0.34). This means that all items are declared valid. While the reliability of the instrument also shows high criteria with a value of $r_{11}$ of 0.75 from the results of extensive trials.

In addition to the requirements of validity and reliability, according to [6], the instruments developed must be adjusted to the purpose, method and time of use. The results of the development instrument will then be used as an observation tool in Biochemistry I courses based on problems with scaffolding. Means that the assessment of creative thinking skills is carried out through verbal activity, namely the delivery of creative thinking in the form of words [10]. The instrument will also be used for self-assessment, which is displayed in a questionnaire form. Self-assessment questionnaire filled by students after following the learning process.

\section{Conclusion}

Observation instruments and questionnaires assessing creative thinking skills were developed following the Borg and Gall model, with steps modified by [11]. The instrument of assessment of creative thinking skills as a result of development, consists of 16 items with each of them having four levels of descriptive scores. The instrument of assessment of creative thinking skills includes five aspects: sensitivity, fluency, flexibility, originality, and elaboration. The instrument has been validated by material experts, constructs, and languages, and declared valid, based on the validity of the items at the stage of limited empirical testing and extensive trials. The instrument also has high reliability from the extensive trial phase.

\section{References}

[1] Ocon, R. (2012). Creative Thinking Teaching Using Problem-based Learning. American Society for Engineering Education. 
[2] Almeida, L. S., Prieto, L. P., Ferrando, M., Oliveira, E., \& Ferrandiz, C. (2008). Torrance Test of Creative Thinking: The Question of Its Construct Validity. Thinking Skills and Creativity3:53-58.https://doi.org/10.1016/j.tsc.2008.03.003

[3] Lee, K.-H. (2005). The Relationship Between Creative Thinking Ability and Creative Personality of Preschoolers. International Education Journal 6(2): 194-199

[4] Runco, M. A., \& Pritzker, S. R. (1999). Encyclopedia of creativity. California: Academic Press/

[5] Arifin, Z. (2013). Evaluation of learning. Bandung: Remaja Rosdakarya.

[6] Arikunto, S. (2012). The basics of educational evaluation. Jakarta: Bumi Aksara.

[7] Purwanto (2011). Evaluation of learning outcomes. Yogyakarta: Student Library.

[8] Wahidmurni, Mustikawan, A., \& Ridho, A. (2010). Evaluation of learning. Yogyakarta: Nuha Litera.

[9] Supardi. 2014, Development of Measurement Instruments for Student Creativity Characteristics. National Seminar on Research Results (SNHP-IV) Institute for Research and Community Service, Semarang PGRI University, December 22, Semarang.

[10] Moma, L., 2015. Development of Mathematical Creative Thinking Ability Instrument for Middle School Students. Journal of Mathematics and Mathematics Education 4(1): 27-41.

[11] Davis, G.A. 2012. Gifted Children and Freedom Education. Jakarta: PT Index/

[12] Kunandar., 2015. Authentic Assessment (Assessment of Student Learning Outcomes Based on Curriculum 2013) A Practical Approach Accompanied by Examples. Jakarta: Rajawali Press.

\section{Authors}

M. Dwi Wiwik Ernawati worked at PMIPA Mathematics Department, University of Jambi, Jambi - Indonesia. Email id: wwkchem2@yahoo.co.id

Damris M. is a professor of Environmental Chemistry, University of Jambi, Jambi - Indonesia from 2003 to present. Email id: damrism@gmail.com

Asrial is a fanfiction author that has written 229 stories for Final Fantasy VII, Final Fantasy VIII, Dragonlance, Harry Potter, Highlander, Shaman King.

University of Jambi, Jambi - Indonesia. Email id: organozinn@yahoo.de

Muhaimin works at Department of Mathematics and Natural Sciences University of Jambi, Jambi - Indonesia. Email id: muhaimin_73@yahoo.de

Article submitted 2019-07-22. Resubmitted 2019-09-03. Final acceptance 2019-09-11. Final version published as submitted by the authors. 